\title{
Estratégias alternativas de negação sentencial na região sul do Brasil: aná- lise da influência de fatores pragmáti- cos a partir de dados do projeto VARSUL
}

Alternative sentential negation strategies in the South Region of Brazil: an analysis of the influence of pragmatic factors based on data from the VARSUL Project.

Marcos Goldnadel Universidade Federal do Rio Grande do Sul Luana Santos de Lima ${ }^{1}$ Universidade Federal do Rio Grande do Sul Gustavo Breunig ${ }^{2}$ Universidade Federal do Rio Grande do Sul Natália Alícia Esquivel ${ }^{3}$ Universidade Federal do Rio Grande do Sul Joana Paim da $\mathrm{Luz}^{4}$ Universidade Federal do Rio Grande do Sul

\section{Resumo}

O português falado no Brasil possui três formas de negação sentencial semanticamente equivalentes: negação pré-verbal, dupla negação e negação em fim de frase. Embora a variante conservadora, a negação pré-verbal, ainda seja predominante, algumas regiões já assistem a um incremento significativo das variantes inovadoras, como é o caso das regiões Nordeste e Sudeste. Esse aumento de ocorrências de formas inovadoras de negação sentencial insere o português falado no Brasil no debate mais amplo sobre o ciclo de Jespersen. Este artigo analisa ocorrências de formas de negação sentencial em entrevistas sociolinguísticas pertencentes ao banco 
de dados do Projeto VARSUL. O levantamento preliminar de ocorrências feito nas três capitais da Região Sul revelou tratar-se de área conservadora no uso da negação sentencial, o que permite considerá-la em um estágio inicial de um processo que, no longo prazo, pode resultar em mudança linguística envolvendo a sintaxe de sentenças negativas. Com o objetivo de identificar os condicionantes para a variante inovadora encontrada na Região Sul e de avaliar a plausibilidade de uma das hipóteses correntes para o surgimento da dupla negação, analisam-se os dados da cidade de Florianópolis.

\section{Palavras-chave}

Dupla negação. ciclo de Jespersen; negação sentencial.

\section{Abstract}

Brazilian Portuguese has three forms of sentential negation semantically equivalent: preverbal negation, double negation and sentence final negation. Although the conservative variant of preverbal negation is still prevalent, innovative variants have had a significant increase in some regions of Brazil, as it can be observed in the Southeast and Northeast regions. This increase of innovative clausal negation forms inserts Brazil in a more comprehensive debate about the Jespersen's Cycle. This article analyzes the different types of negative sentences collected in interviews carried out in the VARSUL Project. The preliminary assessment of occurrences carried out in the three capital cities of the South Region revealed conservative areas regarding negative sentential use. This has allowed us to consider that it is in an initial stage of a process which, in the long run, may result in linguistic change of the syntax of negative sentences. Aiming to identify the possible constraints over the innovative variant found in the South Region and to evaluate the 
plausibility of a current hypothesis for the emergence of double negative sentences, some data from Florianópolis were analyzed.

\section{Keywords}

Double negation; The Jespersen's Cycle; Sentential negation. 


\section{Introdução}

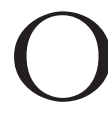

português atualmente falado no Brasil (PFB) possui três estratégias bastante frequentes de negação sentencial'5: negação pré-verbal, dupla negação e negação final, conforme se pode observar em (1) .

(1) a. Eu não quero. (NEG1)

b. Eu não quero não. (NEG2)

c. Quero não. (NEG3)

Esse comportamento do PFB tem sido objeto de estudos de diferentes orientações teóricas, que contribuíram para registrar a incidência significativa de formas de negação não canônicas em diversas localidades.

No Brasil, na perspectiva da Sociolinguística Variacionista, há alguns estudos realizados. Camargos (2000) toma em consideração o falar da cidade de Belo Horizonte; (SOUZA, 2004) observa os usos de negação na comunidade afro-brasileira de Helvécia. Aliando a Teoria da Variação à Sintaxe Gerativa, Cavalcante (2007) analisa dados de inquéritos feitos em comunidades de origem africana de três cidades da Bahia - Cinzento, Rio de Contas e Sapé. Soares (2009) utiliza a Sociolinguística, a Teoria da Acomodação Dialetal e a Teoria das Redes Sociais na análise do fenômeno a partir da observação do contato entre cearenses e cariocas. Na perspectiva funcionalista, Roncarati (1996) investiga o falar de Fortaleza, e Furtado da Cunha (2001), textos orais e escritos pertencentes ao Corpus Discurso E Gramática - a língua falada e escrita na cidade de Natal.

Alguns autores participam do mesmo debate em uma perspectiva mais ampla, situando o fenômeno brasileiro no quadro de discussões mais gerais a respeito do ciclo de Jespersen. O ciclo de Jespersen consiste no processo dia- 
crônico através do qual o operador de negação muda de posição dentro da estrutura frasal. O caso mais mencionado é o do francês, cujo estágio inicial se caracteriza pela manifestação da negação sentencial por meio da anteposição do operador de negação (ne) ao verbo. Ainda nesse estágio, o francês apresenta estruturas de negação enfática, fenômeno recorrente nas línguas, que se caracterizam pelo acréscimo de um item de polaridade negativa em posição pós-verbal. Um desses itens é o substantivo pas (passo), usado inicialmente para expressar ênfase em sentenças com verbos de movimento. Em um estágio subsequente, o substantivo pas passa a expressar ênfase de modo generalizado, não se restringindo apenas a sentenças com verbos de movimento. O próximo estágio é a reinterpretação do pas pós-verbal como uma marca adicional de simples negação, momento em que perde o valor enfático. Há um estágio, portanto, em que a negação em francês ainda é o ne, sendo a partícula pas opcional. Em momento posterior, o pas pós-verbal passa a ser obrigatório, constituindo, juntamente com o ne pré-verbal, uma marca descontínua de negação. Atualmente, no francês, o ne préverbal é opcional, de modo que o pas pós-verbal, obrigatório, consiste na marca efetiva de negação. Com o tempo, é possível que o ne, atualmente opcional, passe à obsolescência, momento em que o ciclo ter-se-á completado.

No debate sobre o ciclo de Jespersen, muito se discute sobre as razões para o surgimento de estruturas alternativas, e redundantes, para realizar a negação sentencial. Esse debate reveste-se de alguma importância nos estudos diacrônicos - especialmente na perspectiva dos estudos de gramaticalização -, uma vez que se discute fundamentalmente o motor da mudança. No caso do português brasileiro, é prematuro afirmar que esteja em curso uma mudança diacrônica em relação à sintaxe da negação. A observação de alguns fatos recomenda cautela nesse sentido. Em primeiro lugar, diferentemente do francês (e do inglês), ocorre uma repetição do mesmo operador de negação. Além disso, esse operador duplicado aprece em posição diferente da encontrada nas línguas que passaram pelo ciclo. Enquanto no francês e no inglês há um estágio em que a segunda marca de negação está necessariamente posposta ao verbo, no português brasileiro a segunda marca negativa aparece necessariamente em fim de sentença. Por fim, no português brasileiro, convivem sincronicamente três formas 
alternativas de negação sentencial - exemplificadas em (1)-(3) -, fenômeno que não ocorreu em francês. Essa convivência de formas caracteriza-se ainda pelo fato de que a negação canônica ainda representa a maioria dos casos, indicando que a dupla negação e a negação em fim de sentença não têm tido força suficiente para desbancar a forma inicial.

De qualquer forma, o estudo das formas de negação sentencial em português brasileiro pode contribuir em alguma medida para o debate mais amplo sobre o ciclo de Jespersen, uma vez que a gênese de determinado tipo de variação encontrada em diversas línguas pode contar com motivações similares. Nessa perspectiva, Schwegler (1991) analisa a negação sentencial no português falado no Brasil a partir de dados coletados em São Paulo, Rio de Janeiro e Salvador. $\mathrm{O}$ autor observa diferenças significativas nos enunciados negativos de resposta a perguntas curtas de abertura de diálogo ${ }^{7}$ entre as cidades de São Paulo e Salvador. Schwegler separa os enunciados analisados em quatro tipos: resposta a pergunta, pergunta, enunciado imperativo e declarativa espontânea. Sua hipótese é a de que o português esteja passando pelo ciclo de Jespersen. Para ele, a dupla negação teria inicialmente uma função de ênfase, que se perdeu com o tempo, assimilando-se ao contorno entonacional da sentença. Nesse novo estágio, a dupla negação teria a função de marcar pragmaticamente informação velha no discurso. Mais recentemente, essa função pragmática teria se perdido nas respostas a perguntas, nas interrogativas e nas imperativas, permanecendo apenas nas declarativas espontâneas.

Schwnter (2005) empreende uma análise pragmática da dupla negação no português brasileiro. Com diversos exemplos bastante convincentes, o autor procura demonstrar que a dupla negação e a negação final são recursos possíveis apenas quando o conteúdo negado é ativado no discurso ${ }^{8}$. Segundo a hipótese defendida, conteúdos novos no discurso e novos para os falantes ou novos no discurso e velhos para os falantes não seriam possíveis com NEG2 ou NEG3. Schwenter (2006) defende a mesma tese a partir da observação de dados do português, do catalão e do italiano. Com os exemplos apresentados, o autor pretende evidenciar o que seria a função pragmática da negação não canônica comum às três línguas investigadas: marcar conteúdo ativado no discurso. A 
constatação feita pelo autor leva-o a supor que o estágio inicial do processo de mudança da posição do operador de negação (ou seja, o estágio inicial do ciclo de Jespersen) seria sempre um momento em que um segundo elemento negativo aparece para marcar informação ativada no discurso.

A observação dos estudos sobre a variação na negação sentencial no Brasil revela que, enquanto as regiões Nordeste e Sudeste contam com estudos que revelam a magnitude do fenômeno, as demais regiões aguardam ainda levantamentos e análises sobre a incidência das três estratégias existentes de negação sentencial. Nas duas regiões já investigadas, os dados têm revelado uma grande incidência de NEG2 e uma quantidade ainda pequena, mas significativa, de NEG3, embora os estudos que tomam por base a região Sudeste não apresentem uma maior sistematização dos dados que permita afirmações mais precisas em termos quantitativos. Os achados feitos nessas duas regiões do país levantam a suspeita de que o português brasileiro esteja passando pelo ciclo de Jespersen.

Resta saber se a variação em questão é um fenômeno localizado em duas regiões que historicamente estão em contato ${ }^{9}$, não ultrapassando suas fronteiras, ou se ocorre nas demais regiões. Além disso, havendo incidência de formas não canônicas de negação sentencial em outras regiões, é preciso identificar a magnitude das ocorrências. Afirma-se, por exemplo, que NEG3 é marca de nordestinismo. No Rio Grande do Sul, a impressão forte é a de que NEG3 tem usos muito restritos, ficando confinada a casos cristalizados - como no enunciado "Sei não" para indicar desconfiança -, mas, até o presente momento, há uma carência de estudos quantitativos dedicados à explorar das estratégias de negação sentencial usadas pelos falantes da Região Sul.

A falta de estudos sobre o fenômeno da dupla negação em outras regiões do país, além de impedir uma visão de conjunto sobre o fenômeno, impossibilita reflexões de caráter mais conceitual, voltadas para a compreensão dos mecanismos envolvidos nos processos de variação e mudança. Nesse caso em particular, essa carência priva a comunidade acadêmica de refletir sobre um fenômeno de variação que, pelo menos em sua origem, parece estar fortemente condicionado por fatores pragmáticos, nível de análise tão pouco considerado nos estudos de variação. 
Este artigo analisa as estratégias de negação sentencial dos falantes da região Sul do Brasil (Rio Grande do Sul, Santa Catarina e Paraná), mais especificamente nas suas capitais, a partir de entrevistas do projeto VARSUL, realizadas no final da década de 80 e início da década de 90, de acordo com os conhecidos critérios para a coleta de dados de fala preconizados pela literatura sociolinguística. O objetivo é verificar se essa região apresenta índices significativos de formas de negação não canônicas e avaliar a influência de fatores linguísticos e sociais no uso das formas variantes.

Para tanto, apresenta-se a suposição da qual parte a análise a ser empreendida, tomada dos estudos de Schwenter, bem como hipóteses sobre as ocorrências de negação não canônica no Brasil e na região Sul do País, discutindo-se o conceito de conteúdo discursivamente ativado, importante elemento da análise a ser empreendida. Em seguida, apresenta-se análise quantitativa realizada na Região Sul, com ênfase nos dados da cidade de Florianópolis, a capital com o maior índice de enunciados negativos não canônicos. Finalmente, as conclusões sugerem uma hipótese para as motivações subjacentes aos usos iniciais de enunciados com negação não canônica, com base nos resultados da análise estatística e em abordagens de outros autores.

\section{Origens das formas não canônicas de negação em português brasileiro: a hipótese de Schwenter e as diferenças regionais no Brasil}

Há algumas hipóteses destinadas a explicar o surgimento de formas redundantes de negação nas línguas. No artigo clássico de Jespersen dedicado ao estudo da negação, publicado originalmente em $1917^{10}$, o autor atribui o acréscimo de uma segunda palavra com valor negativo ${ }^{11}$ à debilidade fonética do operador de negação original. Essa suposição perdeu muito de seu apelo. Grande parte das hipóteses atualmente em competição para a explicação de formas alternativas de negação sentencial partem da suposição de que a dupla negação surge para realizar uma determinada função discursiva. 
É nessa perspectiva que Roncarati associa à dupla negação uma função de preservação da face e considera a negação pós-verbal uma forma de negação despachada. Furtado da Cunha vê na dupla negação uma estratégia de mudança de tópico. Schwegler entende que, diacronicamente, a dupla negação teria sido um recurso de ênfase, tendo-se, posteriormente, integrado ao contorno entonacional dos enunciados, momento em que passou a associar-se à informação velha no discurso. Para ele, também essa função pragmática estaria se perdendo no português falado brasileiro, mantendo-se apenas em enunciados declarativos espontâneos. Por fim, Schwenter, também em uma perspectiva diacrônica, rejeita qualquer associação de formas de negação não canônica - no estágio inicial de utilização - com a função de ênfase, conceito, para ele, vago, difícil de definir em termos precisos e, portanto, de valor duvidoso em uma análise que pretenda estabelecer o contraste entre a forma canônica e as formas não canônicas de negação. Em sua abordagem do fenômeno da negação não canônica, a partir de um levantamento de contextos que parecem bloquear o uso de dupla negação, o autor apresenta uma caracterização pragmática da especificidade de enunciados negativos não canônicos que parece observacionalmente adequada. É nessa caracterização que se fundamenta a abordagem e o tratamento dos dados analisados neste artigo.

Segundo o ponto de vista encontrado em Schwenter (2005, 2006), em suas primeiras aparições nas línguas, enunciados com dupla negação caracterizam-se por marcar o conteúdo proposicional do enunciado negativo como discursivamente ativado. Um conteúdo discursivamente ativado não é o mesmo que um conteúdo pressuposto. Todo conteúdo pressuposto, no sentido clássico do termo, é compartilhado entre os interlocutores. Nem todo conteúdo ativado, no entanto, é conteúdo pressuposto. Caso típico é aquele em que o conteúdo ainda não se encontra confirmado como parte dos conteúdos compartilhados, como na situação de pergunta/resposta, ilustrada em (2).

(2a) A: Pedro, você avisou Helena sobre o cancelamento?

(2b) B: Não.

(2b') B: Não avisei.

(2b”) B: Não avisei não. 
Nesse exemplo, quando o falante A profere o enunciado interrogativo, ativa a proposição "Pedro avisou Helena sobre o cancelamento". Essa proposição, no momento da resposta de B, no entanto, não está pressuposta. Nem poderia estar, já que conteúdo pressuposto é apenas aquele compartilhado entre os interlocutores. Considerando que perguntas são solicitações de informação, seus conteúdos, por definição, não são pressupostos, ou seja, não são compartilhados.

Assim como nem todo conteúdo ativado discursivamente é pressuposto, nem todo conteúdo pressuposto é ativado discursivamente. Todos nós compartilhamos uma quantidade impressionante de conteúdos com nossos interlocutores. A maioria deles não está ativada nas nossas trocas conversacionais, dado que elas se caracterizam pelo intercâmbio de conteúdos tematicamente restritos. Sendo assim, mesmo que uma pessoa pressuponha, em relação ao seu interlocutor, o conteúdo de que o Brasil é um grande produtor de café, esse conteúdo normalmente não estará ativado em uma conversa sobre o campeonato de futebol.

Deve-se, portanto, estabelecer uma distinção muito precisa entre conteúdos ativados e conteúdos pressupostos. Enquanto conteúdos pressupostos são aqueles mutuamente compartilhados entre os interlocutores ${ }^{12}$ - como resultado da troca conversacional em curso, de trocas anteriores ou de compartilhamento cultural -, conteúdos ativados discursivamente são apenas aqueles que, de alguma forma, foram suscitados durante o intercâmbio verbal. Decorre disso que um conteúdo pode ser pressuposto sem estar ativado no discurso, e um conteúdo pode ser ativado no discurso sem estar pressuposto. Nada impede que um conteúdo seja pressuposto e discursivamente ativado, mas é preciso ficar claro que são dois conceitos que envolvem aspectos distintos da interação: pressuposição envolve acordo sobre conteúdos, ativação envolve acessibilidade local de conteúdos.

A hipótese de Schwenter, então, é a de que enunciados com NEG2, nos estágios iniciais de uso nas línguas, marcam pragmaticamente conteúdo discursivamente ativado. Seria por essa razão que, entre as possíveis respostas do falante B em (2), encontram-se formas não canônicas de negação sentencial ${ }^{13}$.

Nesse caso, o conteúdo estaria ativado pela pergunta do falante A. 
Schwenter chama a atenção para o fato de que é a ativação que licencia a negação não canônica, como revela o contraste entre (3) e (4), exemplos do italiano apresentados pelo autor.

(3) A: Chi vieni a prenderti?

(Quem vem te pegar?)

B: Non so. Ma Gianni non ha (*mica) la macchina.

Não sei. Mas o Gianni não tem carro (*não).

(4) A: Chi vieni a prenderti, Gianni?

(Quem vem te pegar, o Gianni?)

B: Non so. Ma Gianni non ha (mica) la macchina.

Não sei. Mas o Gianni não tem carro (não).

Em (3), ao responder ao falante A, o falante B não encontra menção a qualquer indivíduo, o que impediria considerar seu modo de locomoção. Em (4), ao contrário, a menção precedente a um indivíduo poderia fazer supor que ele tivesse um carro. Segundo Schwenter, a não aceitação da resposta em (3), contendo o item de polaridade negativa mica, decorre do fato de não haver no discurso precedente nada que permita inferir que Gianni tem um carro. Em (4), há na pergunta uma referência a Gianni, o que, segundo Schwenter, permitiria, no contexto do diálogo, disparar inferências sobre o seu modo de locomoção, dando relevo à suposição de que ele teria um carro. Só isso seria suficiente para tornar a (suposta) posse de um carro por Gianni conteúdo ativado no discurso (por inferência), o que licenciaria o uso da dupla negação.

O contraste entre (3) e (4) revela que o conteúdo ativado não precisa ter sido veiculado anteriormente de modo explícito no diálogo. Muitos conteúdos tornam-se ativados ao longo das trocas conversacionais por meio dos mais variados tipos de inferência. Um conteúdo pode ser ativado por acarretamento semântico ou lógico, ou por inferências pragmáticas, como implícitos e pressupostos. Por hipótese, todos esses modos de ativação seriam, segundo a suposição de Schwenter, licenciadores dos usos de dupla negação no momento em que essa variante começa a ingressar no sistema linguístico. Para Schwenter, então, 
o aspecto relevante a ser considerado nos casos de negação não canônica é a ativação de conteúdos, e não a o compartilhamento prévio. Um conteúdo compartilhado, mas não ativado discursivamente não é suficiente para licenciar NEG2, como ilustra o exemplo (5).

(5) [Contexto: De manhã, um casal percebe um vazamento no cano da cozinha e liga para o encanador solicitando uma visita sua. $\mathrm{O}$ marido sai e pede para a esposa ficar em casa aguardando o atendimento. Quando chega mais tarde em casa, o marido vai até a cozinha e vê que o cano continua furado. Nesse momento, a esposa entra na cozinha e profere o seguinte enunciado.]

A: O encanador não veio (*não).

Em (5), não basta que a informação de que o encanador não tenha vindo esteja pressuposta (o que fica garantido pela constatação de que o cano continua vazando) para que a dupla negação possa ser usada. Segundo Schwenter, a não aceitação do enunciado com dupla negação decorre do fato de que, mesmo pressuposto, o conteúdo negado, no momento do enunciado, não está ainda ativado discursivamente. Cabe ressaltar ainda que um simples olhar interrogador, um gesto com algum valor discursivo alusivo à vinda do encanador seria suficiente para licenciar NEG2.

A partir de exemplos como esses, Schwenter formula sua hipótese de que formas não canônicas de negação, nos estágios iniciais de uso, estão restritas à expressão de conteúdos ativados no discurso, sendo essa, portanto, a sua função pragmática. Essa função seria encontrada não apenas no português e no italiano, mas também no catalão atual. A limitação pragmática a estruturas não canônicas, típica de uma fase inicial do processo de mudança linguística, no entanto, poderia enfraquecer-se, de modo que a língua, passando por um processo de gramaticalização da nova estrutura, viesse a generalizá-la para os diversos contextos linguísticos. Para o autor, portanto, a função pragmática de marcar conteúdo ativado no discurso seria o estágio inicial experimentado por toda a língua que completou o ciclo de Jespersen. 
O processo de mudança suposto por Schwenter, no entanto, não deve ocorrer de modo abrupto. Sabe-se que, antes de concretizada a mudança em uma área da gramática, a língua passa por estágios intermediários de variação, nos quais condicionamentos sociais e linguísticos operam de modo distinto a cada momento sincrônico analisado. Estando correta a suposição de Schwenter, devese supor adicionalmente que, entre o estágio inicial - de condicionamento pragmático categórico para a negação não canônica - e o estágio final - em que a negação passa a ser pós-verbal -, há estágios intermediários, nos quais as restrições pragmáticas supostas passam a exercer um papel menos impositivo, de modo que a variante inovadora começa a ganhar terreno de forma gradual.

É possível ainda que a variação entre as formas não se apresente de modo similar em diversas regiões de um continuum linguístico, complicando um pouco mais a análise do processo de variação e (possível) mudança. No caso do Brasil, um país de dimensões continentais, esse é um aspecto ainda mais relevante. É possível que o estágio em que se encontre a variação na negação sentencial em determinada região seja mais avançado do que o observado em outra região. Os dados de Schwegler (1991), por exemplo, apontam uma diferença significativa entre os enunciados negativos de Rio de Janeiro e São Paulo, de um lado, e de Salvador de outro, com a cidade nordestina apresentando maior número de ocorrências das variantes inovadoras (NEG2 e NEG3). Um olhar inicial, portanto, faz supor que, em determinadas áreas, a variante inovadora avança com maior rapidez, rompendo barreiras estruturais ainda respeitadas em outras localidades.

Nessa perspectiva, pode-se considerar que resta aos estudos sobre a negação sentencial em português brasileiro muito território a desbravar. Como a breve revisão de literatura feita na introdução deste trabalho procura demonstrar, entre as cinco regiões brasileiras, só há duas estudadas até o momento no que se refere à negação sentencial. Não há estudo contemplando as regiões Norte, Centro-Oeste e Sul, o que limita muito a compreensão do assunto.

Algumas regiões brasileiras, portanto, aguardam estudos que não apenas procurem registrar as ocorrências das formas de negação sentencial, mas ainda que, fundadas em hipóteses plausíveis, procurem ampliar a compreensão dos 
condicionamentos para a escolha das variantes. Este artigo apresenta uma análise sociolinguística de alguns dados da região Sul. Entre os objetivos dessa análise está o de avaliar o papel da restrição pragmática identificada por Schwenter nos dados encontrados em entrevistas do Projeto VARSUL, o que motivou a inclusão, entre as variáveis independentes, da distinção ativado no discurso/não ativado no discurso, por uso literal/inferência.

\section{Dupla negação na região Sul: testando a hipótese de Schwen- ter}

Na seção anterior, foi apresentada a hipótese diacrônica de Schwenter sobre o ciclo de Jesperesen. Para ele, todas as línguas que passaram pelo ciclo experimentaram um estágio inicial com enunciados de dupla negação cumprindo a função de marcar conteúdos ativados no discurso. Essa função, conforme a hipótese do autor, com o tempo, perde sua força, de modo que a dupla negação amplia seu espectro de uso, substituindo de modo sistemático a negação pré-verbal.

No caso do Brasil, os usos de negação diferenciam-se em grande medida entre as diversas regiões. Enquanto a região Sul figura como uma área conservadora, na qual se encontra a variação apenas entre NEG1 e NEG2, mas sem ocorrências de NEG3, a região Nordeste é reconhecidamente uma área de grande incidência de formas não canônicas de negação. Por seu caráter conservador, a região Sul qualifica-se como um ambiente adequado para testar a hipótese de Schwenter, de que a dupla negação surge como marca de informação ativada no discurso. Em áreas como o nordeste brasileiro, em que o uso de formas não canônicas de negação atinge índices elevados, essas pretensas restrições originais podem estar começando a ser relaxadas. Sendo assim, a região Sul, entre as diversas regiões brasileiras, é aquela que, por hipótese, aparece como o melhor candidato para analisar os possíveis condicionamentos pragmáticos para o uso de NEG2 em seus estágios iniciais.

Este trabalho parte da suposição de que, estando correta a hipótese de Schwenter sobre a função pragmática da dupla negação, é na região Sul, pro- 
vavelmente a mais conservadora, que a quantidade de ocorrências dessa modalidade de negação deve ser consideravelmente menor. Além disso, nessa região, essas ocorrências devem ser bastante restritas à função de marcação de informação ativada no discurso. A confirmação dessa expectativa, além de colaborar empiricamente para a comprovação da hipótese de Schwenter, poderá lançar alguma luz sobre a investigação do fenômeno da negação sentencial em outras regiões, uma vez que permitirá investigar em que contextos a inovação avança, rompendo as barreiras da limitação pragmática original em direção a uma possível mudança. A desconfirmação da expectativa, por outro lado, abre o caminho para duas possibilidades interpretativas: ou na própria Região Sul já existe, no momento representado pelos dados analisados, um movimento em direção à mudança, razão pela qual formas não canônicas de negação não mais estariam cumprindo sua função pragmática original de modo categórico, ou a hipótese de que negação sentencial não canônica marca pragmaticamente informação ativada discursivamente está equivocada. Essa última possibilidade abriria caminho para novas hipóteses sobre a função pragmática da negação sentencial não canônica.

Para verificar os usos de negação sentencial na região Sul, inicialmente foram consideradas neste trabalho entrevistas do Projeto VARSUL das três capitais dessa região: Porto Alegre, Florianópolis e Curitiba. Vale lembrar que as entrevistas do VARSUL foram realizadas no final da década de 80 e início da década de 90, momento em que, provavelmente, se pode considerar a variação em um estágio bastante inicial. A investigação contou com duas etapas. Em uma primeira etapa, realizou-se um levantamento bruto de ocorrências das três estratégias (NEG1, NEG2 e NEG3) em um conjunto de nove entrevistas de Curitiba, onze de porto Alegre e nove de Florianópolis. Esse levantamento teve como objetivo verificar a intensidade de uso da estratégia inovadora em cada cidade, a fim de identificar as cidades que, apresentando uma quantidade significativa de ocorrências de negação não canônica, pudessem ser submetidas a uma investigação quantitativa nos moldes variacionistas. Os resultados brutos para as três capitais da região Sul são apresentados na tabela 1 . 


\begin{tabular}{l|c|c|c|c|}
\cline { 2 - 5 } & NEG1 & NEG2 & NEG3 & TOTAL \\
\hline Porto Alegre & $1402 / 99,4 \%$ & $8 / 0,6 \%$ & 0 & 1410 \\
\hline Curitiba & $1371 / 97,4 \%$ & $37 / 2,6 \%$ & 0 & 1408 \\
\hline Florianópolis & $1018 / 95,6 \%$ & $47 / 4,4 \%$ & 0 & 1065 \\
\hline
\end{tabular}

Tabela 1: Formas de negação sentencial nas capitais da Região Sul do Brasil

O primeiro dado que impressiona é a ausência de NEG3 nas três capitais, o que revela um maior conservadorismo em relação a outras regiões já estudadas no Brasil. A quantidade de ocorrências de NEG2 também é bem mais reduzida em relação às outras localidades já estudadas. Porto Alegre destaca-se como a localidade mais conservadora, com uma quantidade muito reduzida de ocorrências de NEG2. Em seguida, vem Curitiba, como um número pouco expressivo de ocorrências da variável inovadora. É Florianópolis a capital da região Sul que apresentou o maior número de ocorrências de NEG2, aproximando-se da expectativa inicial de encontrar em torno de 5\% de ocorrências, percentual que justificaria uma investigação nos moldes variacionistas, mesmo assim, bastante inferior ao verificado em outros estudos.

Considerando a maior incidência de NEG2 em Florianópolis, o que se comprova a partir desse levantamento preliminar, essa capital foi a única que se qualificou para uma investigação nos moldes variacionistas. O estudo apresentado a seguir, no entanto, compõe uma primeira fase da investigação, em que um número ainda reduzido de entrevistas foi submetido a uma codificação com base num pacote de variáveis (a serem apresentadas a seguir). Em função da quantidade ainda reduzida de entrevistas codificadas, o objetivo dessa etapa do projeto é apresentar resultados preliminares para Florianópolis, que indiquem um conjunto de tendências que deverá, na investigação futura, ser reavaliado. Os dados quantitativos a serem apresentados são, portanto, uma projeção inicial, devendo ser entendidos como uma primeira aproximação à questão da variação entre estratégias de negação na Região Sul sob uma ótica investigativa que avalia o papel de fatores pragmáticos na consideração do fenômeno.

\section{A composição da amostra}


Nove entrevistas de Florianópolis foram submetidas a uma codificação a partir de um grupo de variáveis independentes. Nesse primeiro momento, foram analisadas as entrevistas de seis mulheres e três homens. Das seis mulheres, três têm menos de cinquenta anos e três têm mais de cinquenta anos. Cada um desses dois grupos abriga um informante de cada escolaridade (primário, ginásio e segundo grau). Dos três homens, dois têm mais de cinquenta anos, um apenas com primário completo e outro com o segundo grau completo. O homem com menos de cinquenta anos tem o ginásio completo.

\section{As variáveis linguísticas utilizadas na análise das entrevistas de Florianópolis}

A tabela a seguir apresenta as variáveis linguísticas do estudo.

\begin{tabular}{|c|c|c|c|}
\hline \multicolumn{4}{|c|}{ Variáveis Linguísticas } \\
\hline Variável Tipo de enunciado & Codif. & Variável tipo de oração & Codif. \\
\hline Pergunta & $\mathrm{Q}$ & Absoluta & $\mathrm{U}$ \\
\hline Asserção & $\mathrm{K}$ & Principal & $Z$ \\
\hline Respostaa pergunta QU & $\mathrm{R}$ & Coordenada & $\mathrm{C}$ \\
\hline Resposta sim/não & $\mathrm{Y}$ & Rel. Explicativa & $\mathrm{E}$ \\
\hline Variável Posição da frase no turno & & Rel. Restritiva & 8 \\
\hline Inicial & $\mathrm{B}$ & Subst. Obj. & \# \\
\hline Medial & $\mathrm{M}$ & Subst. Subj. & $\&$ \\
\hline Variável Tipo de discurso & & Subst. Compl. & $!$ \\
\hline Direto & $\mathrm{D}$ & Adverbial & (a) \\
\hline Não Direto & $\mathrm{H}$ & Variável status discursivo do conteúdo & \\
\hline Variável posição da oração na frase & & Nãoativadono discurso & $\mathrm{N}$ \\
\hline Começo & $\mathbf{T}$ & Ativado por uso LITERAL na frase imediat. Anterior & $\mathrm{V}$ \\
\hline Meio & + & Ativado por uso LITERAL em frase NẪO imediat. Anterior & $\mathrm{O}$ \\
\hline Fim & $\mathbf{F}$ & Ativado por uso LITERAL em oração anterioma mesma frase & 7 \\
\hline Variável tipo de sujeito & & Ativado por INFERÊNCIA a partir de frase imediat. anterior & $\mathrm{L}$ \\
\hline Não realizado & 4 & Ativado por INFERÊNCIA a partir de frase NÃO imediat. anterior & $\mathrm{J}$ \\
\hline Realizado & 5 & Ativado por INFERÉNCIA em oração anterioma mesma frase & 9 \\
\hline Inexistente & 6 & & \\
\hline
\end{tabular}

Tabela 2: Variáveis utilizadas no estudo da dupla negação na cidade de Florianópolis

A inclusão de quase todas essas variáveis linguísticas teve motivação exclusivamente pragmática. Algumas dessas variáveis foram tomadas de empréstimo a estudos já mencionados, tendo sido vistas como prováveis influenciadoras na escolha entre as possíveis estratégias de negação sentencial. 
A variável tipo de enunciado é encontrada em Schwegler (1991), que percebeu um favorecimento às estratégias não canônicas em enunciados interrogativos e em respostas a perguntas, ambientes em que supôs uma desmarcação da função pragmática original de NEG2 e NEG3, a saber, a de marcar conteúdo velho no discurso.

A variável posição da frase no turno foi escolhida com o objetivo de identificar se o uso de NEG2 e NEG3 está, de alguma forma, relacionado a aspectos interacionais, uma vez que a primeira frase do turno é aquele que se segue ao último enunciado proferido pelo interlocutor.

A variável tipo de discurso inclui duas variantes: discurso direto e discurso não direto. A variante discurso direto codifica porções do discurso em que o falante fala em seu próprio nome. A variante discurso não direto codifica as passagens em que o falante remete à fala de outra pessoa, incluindo o que, em termos gramaticais, se considera discurso direto (a fala de outrem reportada de modo literal) e o que se considera discurso indireto (a fala reportada de modo incorporado no discurso). A divisão proposta não se trata, portanto, da distinção tradicionalmente feita na gramática. A inclusão dessas variáveis decorre da hipótese de que a fala reportada, por suas características expressivas, poderia favorecer a ocorrência de enunciados negativos não canônicos.

Com a identificação da posição da oração negativa na frase, feita através da variável posição da oração na frase, pretendeu-se avaliar se a forma de negação escolhida sofre alguma interferência do status discursivo da oração em que se encontra. Como se sabe, a posição inicial na sequência linear da frase tem um caráter tópico, enquanto a posição final tem um caráter focal. Sendo assim, orações que iniciam a frase tendem a veicular conteúdo ativado, enquanto orações em posição final tendem a apresentar conteúdo novo. Essas características podem, em alguma medida, determinar restrições aos diferentes usos de enunciados negativos.

A variável tipo de sujeito, encontrada em outros estudos, foi incluída em razão de que enunciados negativos não canônicos com sujeito realizado são sentidos como menos naturais. Por alguma razão, que pode ser de ordem prosódica, ou mesmo pragmática, enunciados em que o sujeito está elidido ou 
em que é inexistente (como nos enunciados existenciais) parecem ser mais tolerantes a NEG2 e NEG3.

A variável tipo de oração, embora parta de uma classificação sintática, também tem motivação pragmática. De um modo geral, tem-se observado na literatura um favorecimento às negações não canônicas em orações absolutas. Essas orações, em termos de estrutura da informação, podem se aproximar ou não das orações principais (em determinadas circunstâncias, a principal pode veicular informação focal, em outras não). Essa peculiaridade das principais em relação às absolutas, que tendem a veicular apenas informação focal, pode expressar-se em termos numéricos na quantidade de ocorrências de enunciados negativos ${ }^{14}$. Em relação às coordenadas, em função do nivelamento pragmático que se espera entre todas as coordenadas (tendo todas, por hipótese, o mesmo status informacional), pode-se esperar uma quantidade muito pequena de ocorrências de negação não canônica, já que a negação marcada em apenas uma oração pertencente a uma sequência coordenada instanciaria uma desigualdade em um bloco que se esperaria homogêneo. Quanto às adjetivas, espera-se uma maior tolerância nas explicativas, cujo caráter apositivo sugere a possibilidade de realizar uma negação destacada (e, provavelmente, de caráter enfático). A classificação como substantiva integra o conjunto, mas não permite, sem um cruzamento com outros parâmetros, chegar a muitas conclusões. No caso das objetivas diretas, por exemplo, seria necessário identificar o tipo de verbo que exige complemento. De qualquer modo, os dados podem indicar algum tipo de condicionamento relacionado a essa variante. Por fim, as adverbiais foram incluídas. Como se sabe, as orações adverbiais são um conjunto bastante heterogêneo. Há razões, no entanto, para crer que, mesmo compreendendo um grupo heterogêneo de orações, o rótulo oração adverbial é atribuído, via de regra, a porções de conteúdo intrinsecamente novos ou intrinsecamente velhos, casos em que parece haver um desfavorecimento de realizações não canônicas de negação ${ }^{15}$.

Por fim, a variável status discursivo do conteúdo negado foi incluída para verificar a diretamente a hipótese de Schwenter, segundo a qual NEG2 e NEG3 veiculam, pelo menos em seu estágio inicial de implementação, apenas conteúdo discursivamente ativado. Essa variável é composta por sete variantes. 
A primeira delas registra conteúdo não ativado no discurso. As variantes que registram conteúdo ativado estão divididas em dois grupos: um que identifica conteúdos ativados por uso literal, outro que identifica conteúdos ativados por inferência. Além dessas duas distinções, acrescentou-se mais uma que diz respeito à distância do conteúdo ativado. Com isso, pretendeu-se verificar se o grau de ativação interfere nas escolhas das estratégias de negação.

\section{As variáveis sociais utilizadas na análise das entrevistas de Flo- rianópolis}

As variáveis sociais foram aquelas que o registro original dos dados no projeto VARSUL permite: sexo, faixa etária e nível de instrução. A variável faixa etária inclui apenas duas variantes: falantes com menos de 50 anos e falantes com mais de 50 anos. O banco do VARSUL não contém entrevistas com falantes de nível universitário. Além disso, estabelece uma distinção de nível de escolaridade que utiliza uma nomenclatura escolar adotada à época da coleta, o que permitiu considerar as variantes nível primário, nível ginasial e nível secundário.

\section{Resultados e análise do processamento dos dados}

Ao todo, as nove entrevistas apresentaram um total de 1065 orações com negação. Desse total, apenas 47 orações continham dupla negação, o que corresponde a 4,4\% da amostra. Esses dados estão dispostos na tabela a seguir.

\begin{tabular}{|l|r|r|}
\hline \multicolumn{3}{|c|}{ Número de Ocorrência de NEG1 e NEG2 em Florianópolis } \\
\hline & Número de aplicação & \multicolumn{1}{|c|}{ Percentual } \\
\hline NEG1. Ex.: Eu não vou. & 1018 & $95.6 \%$ \\
\hline NEG2.Ex.: Eu não vou não. & 47 & $4.4 \%$ \\
\hline Total & \multicolumn{3}{|c|}{$1065 / 100 \%$} \\
\hline
\end{tabular}

Tabela 3: Distribuição das ocorrências de estratégias de negação sentencial em nove entrevistas de Florianópolis

A seguir, são apresentados os resultados brutos para todas as variáveis do estudo. A tabela 4 apresenta os dados para a variável tipo de enunciado. 


\begin{tabular}{|l|r|r|r|}
\hline Tipo de enunciado & NEG 1 (quant./porcent.) & NEG2 (quant./porcent.) & Total (quant./porcent.) \\
\hline Asserção & $848 / 96.8 \%$ & $28 / 3.2 \%$ & $876 / 100 \%$ \\
\hline Resposta a pergunta $q u$ & $89 / 90.8 \%$ & $9 / 9.2 \%$ & $98 / 100 \%$ \\
\hline Resposta de perguntasim/não & $56 / 87.5 \%$ & $8 / 12.5 \%$ & $64 / 100 \%$ \\
\hline Pergunta & $25 / 92.6 \%$ & $2 / 7.4 \%$ & $27 / 100 \%$ \\
\hline
\end{tabular}

Tabela 4: Distribuição das ocorrências de estratégias de negação sentencial de acordo com a variável tipo de enunciado

Essa primeira tabela já revela um favorecimento para NEG2 em contextos de resposta. De qualquer modo, cabe registrar a quantidade de 28 ocorrências de NEG2 em enunciados assertivos que não são respostas, revelando que, mesmo em uma região conservadora como Florianópolis, enunciados com negação não canônica não se encontram limitados a contextos de pergunta-resposta.

O levantamento bruto inicial para a variável posição da frase no turno é apresentado na tabela 5 .

\begin{tabular}{|l|r|r|r|}
\hline Posição da frase no turno & NEG 1 (quant./porcent.) & NEG2 (quant./porcent.) & Total (quant./porcent.) \\
\hline Inicial & $125 / 88.7 \%$ & $16 / 11.3 \%$ & $141 / 100 \%$ \\
\hline Medial & $893 / 96.6 \%$ & $31 / 3.4 \%$ & $924 / 100 \%$ \\
\hline
\end{tabular}

Tabela 5: Distribuição das ocorrências de estratégias de negação sentencial de acordo com a variável posição da frase no turno

Os dados da tabela revelam, de modo preliminar, um certo favorecimento a NEG2 na posição inicial do turno. Esse resultado, no entanto, para ser bem avaliado, precisaria ainda ser submetido a um cruzamento com os dados da variável tipo de enunciado. Como se pode ver na tabela anterior, há 17 enunciados com dupla negação que constituem resposta a pergunta. É possível que as 16 duplas negações em posição inicial estejam incluídas nessas 17 respostas a perguntas, de modo que a motivação principal seja aquela, e não esta. De qualquer modo, é importante observar que a quantidade de 31 ocorrências de dupla negação em posição medial revela que não é um fenômeno restrito ao início de turno.

A variável posição da oração na frase resultou nos dados da tabela 6 .

\begin{tabular}{|l|l|l|l|}
\hline Posição da oração na frase & NEG 1 (quant./porcent.) & NEG2 (quant./porcent.) & Total (quant./porcent.) \\
\hline Começo & $500 / 92.9 \%$ & $38 / 7.1 \%$ & $538 / 100 \%$ \\
\hline Meio & $271 / 98.9 \%$ & $3 / 1.1 \%$ & $274 / 100 \%$ \\
\hline Fim & $247 / 97.6 \%$ & $6 / 2.4 \%$ & $253 / 100 \%$ \\
\hline
\end{tabular}

Tabela 6: Distribuição das ocorrências de estratégias de negação sentencial de acordo com a variável posição da oração na frase 
Embora o levantamento pareça indicar algum favorecimento da posição inicial da sentença para a ocorrência de NEG2, esses dados devem ser vistos com muita reserva. Ocorre que, como se verá adiante, de todas as 47 ocorrências de dupla negação, 33 ocorrem em orações absolutas, dados em que se considerou que a oração com dupla negação ocorre no começo da sentença. Tirandose essas 33 ocorrências, restam apenas 14 casos em que a oração com dupla negação ocorre em uma sentença com mais de uma oração.

Para a variável tipo de oração foram encontrados os resultados da tabela 7 .

\begin{tabular}{|l|r|r|r|}
\hline Tipo de Oração & NEG 1 (quant./porcent.) & NEG2 (quant./porcent.) & Total (quant./porcent.) \\
\hline Absoluta & $258 / 88.7 \%$ & $33 / 11.3 \%$ & $291 / 100,0 \%$ \\
\hline Principal & $194 / 97,0 \%$ & $6 / 3,0 \%$ & $200 / 100,0 \%$ \\
\hline Cordenada & $375 / 98.2 \%$ & $7 / 1.8 \%$ & $382 / 100,0 \%$ \\
\hline Relativa Explicativa & $58 / 100,0 \%$ & $0 / 0 \%$ & $58 / 100,0 \%$ \\
\hline Relativa Restritiva & $31 / 31$ & $0 / 0 \%$ & $31 / 100,0 \%$ \\
\hline Substantiva Objetiva & $68 / 98.6 \%$ & $1 / 1,4 \%$ & $69 / 100,0 \%$ \\
\hline Substantiva Subjetiva & $4 / 100 \%$ & $0 / 0 \%$ & $4 / 100,0 \%$ \\
\hline Substantiva Completiva & $15 / 100 \%$ & $0 / 0 \%$ & $15 / 100,0 \%$ \\
\hline Adverbial & $15 / 100 \%$ & $0 / 0 \%$ & $15 / 100,0 \%$ \\
\hline
\end{tabular}

Tabela 7: Distribuição das ocorrências de estratégias de negação sentencial de acordo com a variável tipo de oração

Conforme se pode observar, das 47 ocorrências de dupla negação, 33 figuram em orações absolutas. Das 14 restantes, 6 ocorrem em oração principal, 7 ocorrem em coordenada, e apenas 1, em oração substantiva objetiva. Esse único caso de subordinação é apresentado em (6).

(6) Eu também, eu acho que vocês não se lembram não.

O enunciado (6) contém um verbo epistêmico que serve para expressar uma opinião, de modo que se assemelha muito a uma oração absoluta. Esses dados indicam que, em Florianópolis, no início da década de 90, o fenômeno da dupla negação ainda não havia ingressado nos contextos de subordinação. Essa restrição pode receber dois tipos de explicação. Pode-se supor que exista alguma restrição de ordem sintática; no entanto, é possível que, por suas características pragmáticas, o ambiente da oração subordinada restrinja a dupla negação.

Na tabela 8, estão dispostos os resultados para a variável tipo de sujeito. 


\begin{tabular}{|l|l|l|l|}
\hline Tipo de Sujeito & NEG 1 (quant./porcent.) & NEG2 (quant./porcent.) & Total (quant./porcent.) \\
\hline Realizado & $435 / 95.2 \%$ & $22 / 4.8 \%$ & $457 / 100 \%$ \\
\hline Não Realizado & $453 / 96,0 \%$ & $19 / 4 \%$ & $472 / 100 \%$ \\
\hline Inexistente & $130 / 95.6 \%$ & $6 / 4.4 \%$ & $136 / 100 \%$ \\
\hline
\end{tabular}

Tabela 8: Distribuição das ocorrências de estratégias de negação sentencial de acordo com a variável tipo de sujeito

Os dados indicam que não existe, contrariamente à suposição inicialmente feita, favorecimento à dupla negação em orações que não apresentam sujeito expresso.

A tabela 9 apresenta a variável status informacional do conteúdo negado, inserida no estudo com o objetivo de avaliar a hipótese de Schwenter - a hipótese de que, em seu estágio inicial de implementação, a dupla negação restringe-se à veiculação de conteúdo discursivamente ativado.

\begin{tabular}{|c|c|c|c|}
\hline Status informacional do conteúdo negado & NEG 1 (quant./porc.) & NEG2 (quant./porc.) & Total (quant./porc.) \\
\hline Não ativado no discurso & $463 / 98.9 \%$ & $5 / 1.1 \%$ & $468 / 100 \%$ \\
\hline Ativado por uso LITERAL em oração anterioma mesma frase & $67 / 95.7 \%$ & $3 / 4,3 \%$ & $70 / 100 \%$ \\
\hline Ativado por INFERÊNCIA em oração anterioma mesma frase & $115 / 98,3 \%$ & $2 / 1.7 \%$ & $117 / 100 \%$ \\
\hline Ativado por uso LITERAL na frase imediat. Anterior & $169 / 89.4 \%$ & $20 / 10.6 \%$ & $189 / 100 \%$ \\
\hline Ativado por INFERÊNCIA a partir de frase imediat. anterior & $92 / 89.3 \%$ & $11 / 10.7 \%$ & $103 / 100 \%$ \\
\hline Ativado por uso LITERAL em frase NÃO imediat. anterior & $28 / 100 \%$ & $0 / 0 \%$ & $28 / 100 \%$ \\
\hline Ativado por INFERÊNCIA a partir de frase NÃO imediat. anterior & $84 / 93.3 \%$ & $6 / 6.7 \%$ & 90 \\
\hline
\end{tabular}

Tabela 9: Distribuição das ocorrências de estratégias de negação sentencial de acordo com a variável statusinformacional do conteúdo negado

Antes mesmo da avaliação dos dados processados para a obtenção dos pesos relativos, já se pode depreender, a partir dos dados brutos, um favorecimento à dupla negação de conteúdos discursivamente ativados. É justamente a negação de conteúdos presentes em frase imediatamente anterior, por uso literal ou por inferência, que apresenta uma maior quantidade de ocorrências não canônicas. O contraste entre o número de ocorrências em frases imediatamente anteriores e frases não imediatamente anteriores parece indicar que o grau de ativação tem relevância para a opção pela forma não canônica de negar. Por outro lado, a ocorrência de cinco casos de dupla negação veiculando conteúdo não ativado merece maior atenção, uma vez que, segundo a suposição de Schwenter, esse seria um contexto impeditivo para a dupla negação em comunidades de fala que estejam no estágio inicial de implemen- 
tação da dupla negação - estágio em que se supõe estar a cidade de Florianópolis no momento da coleta dos dados.

Na tabela 10 estão dispostos os resultados para a variável sexo.

\begin{tabular}{|l|r|r|r|}
\hline Sexo & NEG 1 (quant./porcent.) & NEG2 (quant./porcent.) & Total (quant./porcent.) \\
\hline Masculino & $301 / 96.5 \%$ & $11 / 3.5 \%$ & $312 / 100 \%$ \\
\hline Feminino & $717 / 95,2 \%$ & $36 / 4,8 \%$ & $753 / 100 \%$ \\
\hline
\end{tabular}

Tabela10: Distribuição das ocorrências de estratégias de negação sentencial de acordo com a variável sexo

Os dados parecem indicar não haver favorecimento ao uso de dupla negação condicionado pelo sexo, o que se observa também nos dados relativos à variável idade, apresentados a seguir.

\begin{tabular}{|c|r|r|r|}
\hline Idade & NEG 1 (quant./porcent.) & NEG2 (quant./porcent.) & Total (quant./porcent.) \\
\hline De 25 a 49 anos & $489 / 95.1 \%$ & $25 / 4.9 \%$ & $514 / 100 \%$ \\
\hline Mais de 50 anos & $529 / 96,0 \%$ & $22 / 4,0 \%$ & $551 / 100 \%$ \\
\hline
\end{tabular}

Tabela11: Distribuição das ocorrências de estratégias de negação sentencial de acordo com a variável idade

Entre as variáveis sociais, a única que apresentou valores com alguma diferença significativa para a negação sentencial foi a variável nível de instrução.

\begin{tabular}{|l|r|r|r|}
\hline Nível de instrução & NEG 1 (quant./porcent.) & NEG2 (quant./porcent.) & Total (quant./porcent.) \\
\hline Até 4 anos (pimário) & $337 / 93.4 \%$ & $24 / 6.6 \%$ & $361 / 100 \%$ \\
\hline De 4 a 8 anos (ginásio) & $450 / 95.7 \%$ & $20 / 4.3 \%$ & $470 / 100 \%$ \\
\hline Mais de 8 anos (secundário) & $231 / 98.7 \%$ & $3 / 1.3 \%$ & $234 / 100 \%$ \\
\hline
\end{tabular}

Tabela12: Distribuição das ocorrências de estratégias de negação sentencial de acordo com a variável nível de instrução

Os dados brutos revelam uma curva ascendente na direção da baixa escolaridade, o que pode indicar que o fenômeno tenha as pessoas com nível baixo de instrução como impulsionadoras iniciais da variação.

Tendo sido realizado esse primeiro levantamento bruto, passou-se à eliminação das variantes sem ocorrências. Retirados os knockouts, foi feita uma primeira rodada dos dados apenas para a variável NEG2, foco do trabalho. Nessa primeira rodada, o programa indicou quatro variáveis como estatisticamente relevantes, na seguinte ordem de importância: status informacional do conteúdo negado, tipo de 
oração, escolaridade e posição da frase no turno. Nessa primeira apreciação de dados com tratamento estatístico mais confiável, começa a se delinear uma resposta à questão central do estudo. A indicação da importância do status informacional, já nessa primeira rodada, começa a dar sustentação à hipótese de que o uso de dupla negação se encontra fortemente associado à veiculação de conteúdo ativado no discurso. É interessante notar também a variável escolaridade, o que confirma a suposição já feita a partir da análise dos dados brutos de que as camadas com baixo nível de instrução sejam aquelas que dão início a uma difusão mais consistente da forma inovadora ${ }^{16}$.

Depois desse primeiro processamento dos dados, foram realizados os amálgamas. Na variável tipo de enunciado, foram amalgamadas as respostas, juntandose as respostas às perguntas "qu" e as respostas às perguntas "sim/não". Um segundo amálgama realizado foi, na variável posição da oração na frase, a junção da posição medial com a posição final. Um terceiro amálgama foi feito na variável tipo de oração: juntaram-se as orações absolutas com as principais por estarem em ambientes sintáticos que colocam o conteúdo no foreground de atenção. Como havia apenas uma oração subordinada substantiva objetiva, ela foi unida às coordenadas, ambas em ambientes de menor proeminência informacional. Finalmente, na variável status informacional do conteúdo negado foram colocadas sob uma só rubrica as variáveis que identificam o conteúdo como ativado na mesma sentença ou em frase imediatamente anterior e sob uma outra rubrica as variáveis que identificam o conteúdo como ativado em sentença não imediatamente anterior. Com isso, pretendeu-se verificar a importância do grau de ativação na realização de enunciados com dupla negação. Após o processamento dos dados com esses amálgamas, novamente quatro variáveis foram relacionadas como significativas estatisticamente, na seguinte ordem de importância: status informacional do conteúdo negado, tipo de oração, escolaridade e tipo de enunciado.

Em relação ao levantamento feito antes dos amálgamas, a única diferença em relação às variáveis escolhidas como estatisticamente relevantes diz respeito à variável menos significativa entre as quatro selecionadas: enquanto o levantamento anterior indicou para essa colocação a variável posição da frase no turno, o levantamento posterior aos amálgamas indicou a variável tipo de enunciado. A seguir, são 
apresentados os dados para as quatro variáveis estatisticamente relevantes.

A tabela 13 apresenta o resultado da variável tipo de enunciado, considerada a menos relevante entre as quatro variáveis indicadas. Os dados revelam favorecimento à NEG2 nos ambientes de resposta.

\begin{tabular}{|l|r|r|r|}
\hline \multicolumn{1}{|c|}{ Tipo de Enunciado } & Aplicação (NEG2) & Percentual & \multicolumn{2}{c|}{ Peso relativo } \\
\hline Asserção & $28 / 876$ & $3.2 \%$ & 0.45 \\
\hline Resposta & $17 / 162$ & $10.5 \%$ & 0.72 \\
\hline Pergunta & $2 / 27$ & $7.4 \%$ & 0.58 \\
\hline
\end{tabular}

Tabela13: Resultado do levantamento estatístico para a variável tipo de enunciado

A tabela 14 apresenta o resultado da variável tipo de oração.

\begin{tabular}{|c|r|r|r|}
\hline Tipo de Oração & Aplicação (NEG2) & Percentual & \multicolumn{2}{|c|}{ Peso relativo } \\
\hline Or. Absoluta e Principal & $39 / 491$ & $7,9 \%$ & 0.67 \\
\hline Or. Coord. e Subst. Obj. & $8 / 451$ & $1,8 \%$ & 0.31 \\
\hline
\end{tabular}

Tabela14: Resultado do levantamento estatístico para a variável tipo de oração

Esse resultado mostra que o ambiente da oração principal - considerando que as absolutas são também orações principais - é favorecedor de dupla negação. Como foi observado anteriormente, um favorecimento relacionado à variável tipo de oração pode ser explicado em uma perspectiva sintática ou em uma perspectiva pragmática. Em relação aos dados coletados, é preciso lembrar que o segundo grupo apresentado na tabela é composto de sete orações coordenadas em ambiente de oração principal, ou seja, fica evidente que a dupla negação, nos dados coletados, está quase que categoricamente impedida em ambiente de subordinação. A divisão entre absolutas e principais de um lado e coordenadas e substantivas objetivas de outro deve-se ao estatuto pragmático da distinção. Enquanto nos enunciados com dupla negação na oração absoluta e nos enunciados com dupla negação na oração principal o conteúdo colocado no primeiro plano sintático expressa uma só proposição, nos enunciados com dupla negação em coordenadas no ambiente sintático principal há uma sequência de proposições no primeiro plano sintático, o que, em princípio, pelo que se poderia chamar de uma exigência de paralelismo no tratamento pragmático, deve bloquear ocorrências de dupla negação ${ }^{17}$.

A tabelas15 apresenta o resultado da variável nível de instrução. 


\begin{tabular}{|l|r|r|r|}
\hline \multicolumn{1}{|c|}{ Nível de instrução } & Aplicação (NEG2) & Percentual & \multicolumn{2}{c|}{ Peso relativo } \\
\hline Primário & $24 / 361$ & $6.6 \%$ & 0.69 \\
\hline Ginásio & $20 / 470$ & $4.3 \%$ & 0,49 \\
\hline Segundo grau & $3 / 234$ & $1.30 \%$ & 0.23 \\
\hline
\end{tabular}

Tabela15: Resultado do levantamento estatístico para a variável nível de instrução

Os dados mostram um aumento do favorecimento do uso da variante inovadora à medida que se reduz o nível de instrução do falante. Por fim, a tabela 16 apresenta os dados da variável considerada a mais importante pelo programa: status informacional do conterido negado.

\begin{tabular}{|l|r|r|r|}
\hline Status informacional do conteúdo negado & Aplicação (NEG2) & Percentual & Peso relativo \\
\hline Não ativado no discurso & $5 / 468$ & $1,1 \%$ & 0.21 \\
\hline $\begin{array}{l}\text { Ativado no discurso de forma literal ou inferêncial na } \\
\text { mesma sentença ou em frase anterior }\end{array}$ & $34 / 362$ & $9,4 \%$ & 0.78 \\
\hline $\begin{array}{l}\text { Ativado no discurso de forma literal ou inferêncial em } \\
\text { frase ou oração não anterior }\end{array}$ & $8 / 207$ & $3.9 \%$ & 0.64 \\
\hline
\end{tabular}

Tabela16: Resultado do levantamento estatístico para a variável status informacional do conteúdo negado

Os resultados para essa variável são bastante contundentes. Percebe-se um claro favorecimento à utilização de dupla negação em sentenças cujo conteúdo esteja previamente ativado no discurso. É interessante observar ainda a influência da proximidade do conteúdo ativado: conteúdos ativados em enunciado imediatamente precedente favorecem mais a dupla negação, indicando que o grau de ativação pode ter algum papel. A seleção dessa variável como a mais significativa aponta para a possibilidade de que a hipótese de Schwenter esteja correta. Esse levantamento feito pelo estudo, ainda incipiente, já que realizado com um número limitado de entrevistas, mantém a expectativa de que a ativação de conteúdos seja o fator determinante para o ingresso de enunciados com dupla negação no sistema linguístico.

Os casos em que a dupla negação veicula conteúdo considerado não ativado no discurso, no entanto, merecem atenção, porque contrariam frontalmente a hipótese que estamos tomando como correta. Para compreendê-los, há duas explicações possíveis. A primeira leva em consideração as duas prosódias distintas encontradas em enunciados com dupla negação, associadas a diferentes funções pragmáticas. A observação de enunciados com negação não canônica permite iden- 
tificar dois tipos de realização prosódica: uma associada a usos enfáticos, em que a negação final parece expressar-se através de um aumento de intensidade, e uma associada a usos não enfáticos - na verdade, curiosamente, trata-se de usos atenuadores, em que o falante parece demonstrar sua discordância de modo bastante polido -, em que a negação final parece expressar-se através de uma diminuição de intensidade. A hipótese de Schwenter aplica-se somente aos usos não enfáticos, os únicos reconhecidos por ele. A existência de enunciados negativos não canônicos enfáticos, portanto, consiste em fenômeno distinto, e os casos em que veiculam conteúdos não ativados não constituem contraexemplos à hipótese do autor. Esse é o caso de duas das ocorrências (das cinco) encontradas no corpus em análise, apresentadas a seguir ${ }^{18}$.

(6) F: Meus irmãos, não. Meus irmãos eram bem calmos, estudiosos, filhos exemplares, né? Meio bobões, pra mim, muito calmos pro meu gosto. Agora, eu e a minha irmã... Muito, muito calmos. Nunca fizeram nada, não faziam arte nenhuma. Tinham muito medo do meu pai, né? Porque eram homens, daí podiam entrar na...podiam apanhar, podiam tudo, né? E mulher, né, o negocio era mais... O meu pai dava mais atenção, o meu avô. O resto não, o homem entrava no pau mesmo. Não tinha essa estória, não. É, o meu avô tinha, não era relho, como é que se diz aquelas varas, mas não é vara de marmelo. Aquelas varinhas aí, como é que falam?

\section{E: Chicote.}

F: Não é chicote. Chicote é demais, né? Ô, o pessoal também não é assim, não era tão indomável, né? É, aquelas varinhas de galho de árvore mesmo, bem fininha. Tinha, tinha. Mas mulher nunca entrava, nunca apanhava. O negócio era homem. Homem entrava mesmo. Não tinha essa estória não.

Nessa passagem, a entrevistada falava do fato de que os homens apanhavam. A escuta da passagem não deixa dúvida de que se trata de um uso enfático, caso em que a dupla negação pode veicular conteúdo não ativado.

O maior problema a ser enfrentado, no entanto, diz respeito aos enunciados 
com negação não canônica atenuadora, aqueles que Schwenter considera restritos à função de veicular conteúdo discursivamente ativado. Para entender a ocorrência desses casos, é necessário lembrar que o conteúdo negado em um enunciado negativo não canônico pode ter sido anteriormente ativado de modo inferencial. Durante o processo de discussões que antecederam as codificações dos enunciados das entrevistas de Florianópolis, tentou-se delimitar de modo muito preciso as fontes de conteúdos inferíveis, identificando-se os recursos inferenciais responsáveis pela ativação de conteúdos. Optou-se por se considerar conteúdo inferível apenas aquele que resultasse de acarretamento, pressuposição ou implicatura. Os conteúdos que não se enquadraram nessa classificação foram considerados não ativados. Há, contudo, fenômenos pragmáticos de outras ordens que parecem contribuir para a ativação de conteúdos, e talvez sua consideração pudesse levar a uma reclassificação dos três casos restantes de negação não canônica não enfática. Esses três casos são apresentados a seguir.

(7) Agora não, todo mundo tem carro, quer dizer, que carro hoje em dia é uma necessidade. Não é luxo. É uma necessidade. Tu vês: tenho quarenta mil, não sei, se a mulher quiser comprar um carro, ela compra. Eu não quero mais carro não, porque eu não pago nem passagem. Eu já passei da idade. Eu vou comprar carro pra quê?

Nessa passagem, observa-se uma alternância entre SNs tópicos: o pronome eu (referindo-se ao entrevistado) e a mulher (referindo-se à esposa do entrevistado). Antes de realizar o enunciado com dupla negação, o entrevistado cogita a possibilidade de sua esposa querer comprar um carro. Em seguida, refere-se a si mesmo através do pronome eu realizando um tópico contrastivo. Com esse enunciado nega o desejo de comprar carro, já anunciado no enunciado anterior. É justamente a construção de tópico contrastivo que parece tornar ativo o conteúdo relativo ao desejo do falante de comprar um carro. Sentenças com tópico contrastivo, no entanto, não foram incluídas na lista de fontes de inferência a serem consideradas na análise dos dados.

O caso apresentado a seguir é de outra natureza. 
(8) E: E qual a outra novela que você vê?

F: Eu assisto o Mico Preto, não... não sou muito ligada, não. Assisto as três, mas não... não presto atenção.

Antes dessa passagem, a entrevistada já havia mencionado outras novelas a que assistia. Como ela havia dito que acompanhava as outras novelas, quando respondeu que assistia à novela Mico Preto, pode ter pensado que o entrevistador pudesse considerar que ela acompanhava essa novela do mesmo modo que as demais. Embora essa não seja uma implicatura típica, parece uma inferência possível. Nesse caso, a falante nega um conteúdo que poderia ter sido inferido em função de conteúdo prévios.

O último caso oferece alguma dificuldade. A impressão que o enunciado passa é a de que a entrevistada imaginou que a pergunta do entrevistador permitiria uma inferência de caráter bastante vago.

(9) E: E a senhora era vaidosa, quando era menininha, mocinha?

F: Não, não era vaidosa, não. Toda vida fui simples. Não gosto de certas coisas não.

Aqui há dois enunciados com negação não canônica, mas apenas o segundo consiste em um contraexemplo à hipótese postulada. O problema é que a entrevistada parece levar muito adiante as inferências que poderiam ser geradas pela pergunta da entrevistadora. Ao que tudo indica, por alguma razão, considerou que admitir alguma vaidade seria admitir gostar de certo tipo de coisa que desaprova. Não resta dúvida sobre o fato de que a entrevistada, com essa resposta, está se mostrando uma pessoa reservada e até mesmo pudica. Cabe ao ouvinte, no entanto, preencher o vazio interpretativo deixado pela expressão certas coisas. Aqui talvez se pudesse falar, como na literatura sobre pressuposições, de acomodação de determinado conteúdo no contexto. O falante é levado a acomodar a ideia de que alguém que é vaidoso também gosta de outras coisas específicas, as "certas coisas" negadas no enunciado final da passagem.

Todos os três casos inicialmente classificados como ocorrências de dupla negação atenuadora veiculando conteúdo não ativado parecem, portanto, ser casos 
em que, na verdade, o conteúdo está ativado. A sua classificação como não ativado decorreu do estabelecimento prévio de critérios precisos, a fim de que todo o grupo de pessoas envolvidas com a codificação dos dados contasse com diretrizes muito claras para seu trabalho.

\section{Considerações finais}

O fenômeno da variação de posição do operador de negação sentencial não é uma peculiaridade da língua portuguesa. Essa mesma variação pode ser encontrada atualmente no francês ${ }^{19}$, no catalão e em algumas variedades do espanhol. Algumas línguas germânicas, como o inglês e o belga, também experimentaram, ao longo do tempo, mudança nos padrões oracionais para a expressão da negação sentencial. A discussão sobre essa mesma variação no português, particularmente na variante falada no Brasil, insere-se, portanto, no quadro mais geral do que se convencionou chamar de ciclo de Jespersen. Nesse sentido, uma das indagações centrais do debate sobre a variação encontrada em enunciados negativos do português brasileiro é a que diz respeito à possibilidade de que essa variedade esteja passando por um processo de mudança do padrão de negação sentencial, ou seja, de que esteja passando pelo ciclo de Jespersen.

Independentemente do que se possa supor para o desenvolvimento do fenômeno em português - um futuro apontando para a mudança ou para a coexistência entre as formas variantes -, uma outra questão mais geral se impõe: o que dá origem ao ciclo de Jespersen? Considerando-se que uma grande quantidade de línguas experimenta processos de variação e mudança tão similares, a pergunta reveste-se de alguma importância em diversos âmbitos: da Sociolinguística, da Linguística Histórica e, dependendo da explicação encontrada, da Sintaxe ou da Pragmática. Para se responder à pergunta, é necessário investigar o momento inicial de variação em cada língua particular.

Duas têm sido as hipóteses para explicar o surgimento de formas redundantes de negação nas línguas que atestam variação em sentenças negativas. A primeira é a do próprio Jespersen, para quem o surgimento de um segundo elemento negativo na sentença decorre de um processo de erosão fonética do 
operador de negação pré-verbal. Segundo esse ponto de vista, em um primeiro momento, a negação pré-verbal sofreria uma redução formal, tornando-se débil. Essa debilidade inicial prejudicaria a compreensão, exigindo um reforço adicional. Um segundo elemento, então, já disponível no repertório linguístico passaria a ser usado como forma de garantir a inteligibilidade de enunciados negativos, dada a importância da distinção entre afirmações e negações.

Explicações como a de Jespersen não são atualmente limitadas ao fenômeno da negação. Muito da literatura sobre gramaticalização postula uma associação entre erosão fonética e gramaticalização. Em muitos casos, o problema é, conforme bem observa Lehman (1995), identificar o que causa o quê: a redução dá início a uma mudança, ou a mudança decorre de outras causas e acaba por determinar a redução? Em relação ao ciclo de Jespersen, (HOEKSEMA, 2009) considera improvável a redução de um elemento tão importante como a negação. O autor insere-se no grupo que adere à segunda hipótese explicativa, segundo a qual um novo elemento negativo surge como recurso de ênfase, normalizando-se com o tempo e substituindo gradativamente a negação original. Outro estudo que adota essa explicação é o de Awera (2009).

Há ainda uma terceira hipótese, um tanto quanto isolada, a defendida por Schwenter e já exposta neste artigo. O autor evita lançar mão do conceito de ênfase, para ele, muito impreciso para cumprir algum papel na explicação de fenômenos linguísticos. Com base em exemplos, defende a ideia de que a dupla negação surge para cumprir a função pragmática de registrar conteúdo discursivamente ativado.

Quando se observa o caso brasileiro, no entanto, algumas dúvidas são inevitáveis. Sabe-se que a dupla negação no Brasil, de um ponto de vista expressivo, cumpre, em muitos os casos, uma função atenuadora, oposta, portanto, à ênfase postulada para outras línguas. Isso é o que observa Roncarati (1996) em um estudo que tomou por base dados obtidos a partir de testes com universitários de Fortaleza. Em outras línguas, é improvável que a dupla negação cumpra uma função similar, dado que, diferentemente do que ocorre em português (em que a segunda negação é apenas uma cópia da primeira), o novo elemento negativo costuma ser um item de polaridade negativa, mais especifi- 
camente um minimizador, que, nos estágios iniciais - quando ainda não se gramaticalizou - tem um valor nitidamente enfático ${ }^{20}$.

A opção do português por uma cópia do advérbio de negação neutro abre, portanto, a possibilidade de enunciados com dupla negação que não se caracterizem pela ênfase. Isso não significa, no entanto, que a dupla negação em português não possa servir a propósitos enfáticos. Schwegler (1991) afirma que a dupla negação em português europeu só ocorre para expressar ênfase. No Brasil, a observação da fala revelará que as duas funções pragmáticas estão disponíveis. Encontram-se enunciados com dupla negação enfática e com dupla negação não enfática, sendo este último tipo o mais frequente. Há, no entanto, diferenças prosódicas entre os enunciados cumprindo as funções distintas. Sousa (2009), um estudo da prosódia de enunciado negativos, observa que enunciados com dupla negação apresentam uma elevação de altura em todo o enunciado, com uma queda significativa apenas no não final. Esse é o padrão da dupla negação não enfática. Para os casos de dupla negação enfática no português brasileiro, em número mais reduzido, a literatura especializada não tem dado atenção, mas é possível perceber que o padrão prosódico se caracteriza por um aumento de altura na negação final, o contrário do caso não enfático.

Quase todos os casos de dupla negação analisados nos levantamentos apresentados neste artigo são não enfáticos. Dada a reduzida quantidade de casos de dupla negação coletados, tudo indica que os dados de Florianópolis caracterizam um momento inicial de utilização da variável inovadora. Além disso, esses dados, submetidos à investigação quantitativa, confirmaram a variável status informacional do conteúdo negado como a mais relevante para a aplicação da regra de duplicação da negação. Tudo isso parece indicar que Schwenter está correto em afirmar que a dupla negação surge como recurso pragmático de marcação de ativação discursiva de conteúdo.

No entanto, a existência de casos de dupla negação enfática, muito reduzidos, mas ainda observáveis, pode estar a indicar uma quarta via explicativa. É possível que, na linha do que defendem Awerae Hoeksema, o primeiro momento experimentado pela língua portuguesa seja o da ênfase ${ }^{21}$. Como o elemento responsável pela ênfase, o segundo não em posição final de frase, é mo- 
nossilábico, sendo de realização consideravelmente débil, viabiliza a realização de um contorno prosódico distinto do original (o da ênfase). Nesse novo contorno, observado em Sousa (2007), o conteúdo do enunciado parece colocado em função de tópico. Essa configuração explica formalmente o fato de que o conteúdo da sentença deve estar ativado ${ }^{22}$. Nada mais natural que a situação assim seja, uma vez que se todo conteúdo tópico deve estar ativado²3.

Se essas intuições estão corretas, os dados de Florianópolis representam não um primeiro estágio da variação, mas um segundo, aquele em que os usuários da língua passaram a utilizar a dupla negação com um contorno prosódico apropriado para a sinalização de que o conteúdo proposicional da sentença tem caráter tópico. Segundo essa análise, enunciados como a resposta de $(10)^{24}$ devem receber a análise sugerida a seguir.

(10) E: E das brincadeiras de roda, a senhora lembra algum canto, alguma coisa assim?

F: Não. [De roda assim eu não brinquei muitoT] [não].

Nessa análise, todo o conteúdo proposicional do enunciado, tópico da conversação já estabelecido na pergunta, encontra-se apresentado formalmente como tópico.

Essa forma de descrever os fatos explica a incidência significativa de NEG2 em respostas a perguntas - identificada neste ${ }^{25}$ e em outros estudos. No trecho em (10), por exemplo, o tópico estabelecido pela pergunta é a participação da entrevistada em brincadeiras de roda ${ }^{26}$.

Nessa perspectiva, o presente estudo concorda parcialmente com as duas hipóteses de cunho pragmático. A dupla negação, muito provavelmente, surge como um recurso de ênfase entre os tantos disponíveis na língua ${ }^{27}$. Sendo assim, é preciso concordar com Awera (2009) no que se refere à motivação inicial para o surgimento da dupla negação. A investigação realizada neste estudo, com dados do início da década de 90 em Florianópolis, indica, no entanto, que a intuição de Schwenter precisa ser considerada. No momento em que a negação passa de enfática a não enfática, como parece ser o caso de Florianópolis 
no período investigado, a análise quantitativa realizada indica um forte condicionamento pragmático do estatuto informacional do conteúdo negado. A seleção pelo programa estatístico da variável status informacional do conteúdo negado como a mais relevante aponta para a importância das observações de Schwenter.

As outras variáveis linguísticas selecionadas como relevantes para a realização de NEG2 também indicam a necessidade de investir em uma abordagem pragmática para o fenômeno. Além do sugestivo aumento de ocorrências de NEG2 em respostas, indicando, um forte condicionamento pragmático, a distribuição das ocorrências observada entre os tipos de oração - muito similar, por exemplo, à encontrada em (SOARES,2009) - também aponta para a via de análise pragmática, dado que às funções sintáticas associam-se funções comunicativas, muitas das quais merecem ainda maior investigação teórica.

Por fim, vale ressaltar que as conclusões aqui apresentadas são preliminares. Os resultados obtidos baseiam-se ainda num número reduzido de entrevistas para os padrões variacionistas. De qualquer forma, a análise quantitativa realizada impressiona pela consistência com a hipótese de Schwenter, estimulando a continuidade da investigação nos moldes variacionistas com um número maior de dados. A confirmação da hipótese de que, em um estágio inicial, a dupla negação está condicionada pelo status informacional do conteúdo negado certamente significará um impulso decisivo para a compreensão das etapas envolvidas no ciclo de Jespersen, isso porque, uma vez identificadas certas restrições originais, estudos em outras comunidades em que o fenômeno está mais generalizado, como é a região Nordeste do Brasil, podem passar a investigar em que medida e em que contextos essas restrições passam a ser relaxadas, promovendo uma maior compreensão da trajetória de variação. Essa compreensão, mais do que permitir uma descrição adequada dos fatos, possibilitará uma reflexão de qualidade sobre o modo como os sistemas linguísticos se modelam, no decurso do tempo, a partir do surgimento de novas formas de expressão. 
Referências

AWERA, J. V. D. The Jespersen Cycles. In: GELDEREN, E V. Cyclical change. Amsterdan: John Benjamins, 2009, p. 35-71.

CAMARgos, M. (2000). A negativa: uma análise qualitativa. Disponível em http://www.ufop.br/ichs/conifes/anais/LCA/clca03.htm. Acessado 12 de janeiro de 2012.

CAVALCANTE, R. A negação pós-verbal no português brasileiro: análise descritiva e teórica de dialetos rurais de afro-descendentes. 2007. 160 f. Dissertação (Mestrado em Linguística) - Instituto de Letras, Universidade Federal da Bahia, Salvador, 2007.

FURTADO DA CUNHA, M. A. O modelo das motivações competidoras no domínio funcional da negação. DELTA: Documentação de Estudos em Lingüística Teórica e Aplicada, São Paulo, v. 17, no 1, p. 1-30, 2001.

FURTADO DA CUNHA, M. A. Grammaticalization of the strategies of negation in Brazilian Portuguese. Journal of Pragmatics, Amsterdam, v. 39, p. 1638-53, 2007. HOEKSEMA, J. Jespersen recycled. In: GELDEREN, E V. Cyclical change. Amsterdan: John Benjamins, 2009, p. 15-34.

JESPERSEN, O. Negation in English and other languages.In: JESPERSEN, O. Selected writings of Otto Jespersen. New York: Routledge, 2010, p. 2-80.

LAMBRECHT, K. Information structure and sentence form: topic, focus and the mental representation of discourse referents. Cambridge: Cambridge University Press, 1994.

LEHMAN, C. Thoughts on grammaticalization. Munique: Lincom Europa, 1995.

RONCARATI, C. N. S.. A negação no português falado. IN: MACEDO, A. T.; RONCARATI, C. N. S.; MOLLICA, M. C. M. (orgs.). Variação e Discurso. Rio de Janeiro: Tempo Brasileiro, 1996, p. 97-112.

SCHWEGLER, A. Predicate negation in contemporary Brazilian Portuguese: a change in progress. Orbis, Leuven, v.34, p. 187-214, 1991.

SCHWENTER, S. A. The pragmatics of negation in Brazilian Portuguese. Lingua, Amsterdam,v. 115, p. 1427-56, 2005.

SCHWENTER, S. A. Fine-Tuning Jespersen's Cycle. In: Birner, B.; Ward, G. 


\section{Drawing the Boundaries of Meaning: Neo-Gricean Studies in Pragmatics} and Semantics in Honor of Laurence R. Horn. Amsterdam: Benjamins, 2006, p. 327-344.

SOARES, V. A negação no contato entre dialetos. 2009. 113f. Dissertação (Mestrado em Linguística) - Universidade Federal do Rio de Janeiro, Rio de Janeiro, 2009.

SOUSA, L. T. A gramaticalização do não no português brasileiro e a etapa do processo. Domínios de Linguagem, Uberlândia, no 2, p. 1-16, 2007.

SOUZA, A. S. (2004). As estruturas de negação em uma comunidade rural afro-brasileira:Helvécia-BA. [online]. Disponível em http://www.vertentes. ufba.br/souza.doc. AcessadoemMaio de 2009.

STALNAKER, Robert C. Pragmatic pressupositions. In: DAVIS, Stephen (Org.). Pragmatics: a reader. Oxford: Oxford University, 1991, p. 471-481.

${ }^{1}$ Luana Santos de Lima é aluna do curso de mestrado do Programa de Pós-Graduação em Letras da Universidade Federal do Rio Grande do Sul.

${ }^{2}$ Gustavo Breunig foi aluno de graduação da UFRGS, tendo sido, na época de produção do artigo, bolsista de iniciação científica do grupo de pesquisa vinculado ao Projeto Pressuposição e estados de crença: uma abordagem inferencial do problema da projeção, coordenado pelo prof. Dr. Marcos Goldnadel. Atualmente, Gustavo Breunig é aluno do curso de mestrado do Programa de Pós-Graduação em Letras da Universidade Federal do Rio Grande do Sul.

${ }^{3}$ Natália Alícia Contin Esquivel foi aluna de graduação da UFRGS, tendo sido, na época de produção do artigo, bolsista de iniciação científica do grupo de pesquisa vinculado ao Projeto Pressuposição e estados de crença: uma abordagem inferencial do problema da projeção, coordenado pelo prof. Dr. Marcos Goldnadel

4Joana Paim da Luz é aluna de graduação da UFRGS, tendo sido, na época de produção do artigo, bolsista voluntária de iniciação científica do grupo de pesquisa vinculado ao Projeto Pressuposição e estados de crença: uma abordagem inferencial do problema da projeção, coordenado pelo prof. Dr. Marcos Goldnadel.

${ }^{5}$ Esse é um entre os tantos aspectos em que o português brasileiro se diferencia do português europeu, que apresenta uma quantidade muito reduzida de casos de dupla ne- 
gação, e apenas com valor enfático (cf. Schwegler, 1991).

${ }^{6}$ Costumam-se identificar os três padrões apresentados, respectivamente, com as siglas NEG1, NEG2, NEG3, rótulos que doravante passam a ser utilizados.

${ }^{7}$ Trata-se de respostas a perguntas feitas a transeuntes, como "Você tem fósforos?", "Você sabe onde fica a rua X?".

${ }^{8} \mathrm{~A}$ distinção entre conteúdo compartilhado entre os interlocutores e conteúdo ativado no discurso é apresentada mais adiante neste artigo.

${ }^{9}$ É fato que existe uma migração permanente de pessoas da região Nordeste para a região Sudeste.

${ }^{10} \mathrm{O}$ artigo pode ser encontrado em Jespersen (2010), uma publicação recente contendo diversos artigos do autor.

${ }^{11}$ Hoeksema (2009) lista os diversos tipos de palavras e construções normalmente disponíveis para a realização de negação nas línguas naturais.

${ }^{12}$ Adoto aqui a concepção clássica de pressuposição do falante, encontrada em Stalnaker (1974), segundo a qual os conteúdos pressupostos pelos falantes em uma troca conversacional são aqueles que consideram mutuamente compartilhados. Embora essa concepção tenha sido questionada com bastante propriedade, por exemplo, em Sperber e Wilson (1986), esses autores admitem a necessidade de incorporar na descrição de fenômenos pragmáticos alguma ideia de mutualidade (cf. o conceito de manifestabilidade mútua encontrado nesses autores). Para os propósitos desse artigo, a concepção clássica é suficiente.

${ }^{13}$ Para o autor, as formas não canônicas só são aceitáveis quando o conteúdo é ativado. Nada impede, no entanto, que sejam usadas as formas canônicas para veicular conteúdo ativado discursivamente, como em (1b) e (1b').

${ }^{14}$ Supondo, evidentemente, que há alguma interação entre formas de negar e a estrutura informacional dos enunciados.

${ }^{15}$ Nessa apresentação sumária das variáveis não é possível desenvolver em maior detalhe as suposições sobre as restrições pragmáticas a enunciados negativos. Em outro artigo, em preparação, apresenta-se uma análise da pragmática da dupla negação segundo a qual os enunciados desse tipo exigem que o conteúdo não seja apenas ativado (como postula Schwenter), mas também tópico.

${ }^{16}$ É preciso, no entanto, ser prudente em relação às conclusões que podem ser extraídas do levantamento feito. Em virtude do número reduzido de entrevistas sociolingüísticas consideradas, trata-se, como foi mencionado anteriormente, de uma primeira aproxi- 
mação ao fenômeno da dupla negação. No que diz respeito ao que se pode inferir a partir da consideração das variáveis sociais, a prudência deve ser maior ainda.

${ }^{17}$ De qualquer forma, o caso das coordenadas é mais complicado do que essas observações podem sugerir. São agrupados, sob o rótulo da coordenação sintática, muitos tipos de oração com características pragmáticas bastante distintas. A observação qualitativa dos dados, a ser apresentada em outro artigo, revelou, por exemplo, que as coordenadas adversativas são favorecedoras da dupla negação, em virtude das inferências pragmáticas associadas ao uso de conjunções adversativas.

${ }^{18}$ Diferentemente de Schwenter, assumimos que, antes do estágio da dupla negação atenuadora, há um estágio inicial de dupla negação enfática. O surgimento da dupla negação atenuadora está associado a outra realização prosódica do enunciado, mas não elimina os usos enfáticos, dos quais se diferencia justamente pela prosódia. Há um momento, portanto, em que os dois tipos de enunciados convivem (enfáticos e atenuadores). Nossa hipótese é a de que, nesse estágio, apenas as negações não canônicas atenuadoras veiculam conteúdo ativado.

${ }^{19} \mathrm{O}$ caso mais conhecido é o do francês, que passou por estágios distintos caracterizados por diferentes tipos de dupla negação. Atualmente, existe uma alternância entre "ne V pas" e "V pas".

${ }^{20} \mathrm{O}$ português também tem minimizadores. Um exemplo é o substantivo pingo em frases como "Ele não tem um pingo de consideração". Nas línguas em que o novo elemento negativo surge a partir de minimizadores (como é pingo em português), dificilmente se poderá considerar uma função atenuadora a do novo elemento negativo no estágio inicial de variação linguística.

${ }^{21}$ Estágio em que Portugal teria estacionado.

${ }^{22} \mathrm{O}$ próprio Schwenter considera a dupla negação uma estratégia de topicalização.

${ }^{23} \mathrm{O}$ conteúdo tópico, nos casos não marcados está ativado. A exceção são os casos em que um elemento não tópico e não ativado é alçado à posição de tópico, como nas estruturas apresentativas (cf. Lambrecht, 1994).

${ }^{24} \mathrm{O}$ exemplo é retirado de entrevista analisada do VARSUL.

${ }^{25}$ Neste estudo, a variável tipo de enunciado foi selecionada como relevante para a realização de NEG2, em que as respostas favorecem o uso da variante inovadora, com peso relativo de 0.72 .

${ }^{26} \mathrm{O}$ curioso, nesse caso, é a presença de um segundo tópico nominal expresso pela anteposição do sintagma de roda. 
${ }^{27}$ Em português, por exemplo, há muitos recursos para expressar a ênfase da negação. Um muito utilizado é o quantificador nada em fim de frase, como em i.

(i) A: E o Pedrinho? Já avisou o pai sobre o vidro que quebrou na escola? B: Não avisou nada!

Diferentemente da dupla negação abordada neste estudo, construções como a encontrada em (i) jamais podem despir-se de seu valor enfático.

Data de submissão: 07/06/2012 